\title{
The Untapped Potential of Nitroproteomics for Medicine
}

\author{
Xianquan Zhan ${ }^{1,2,3,4^{*}}$, Shehua Qian ${ }^{1,2,3}$, Yuda Huang ${ }^{1,2,3}$ \\ ${ }^{1}$ Key Laboratory of Cancer Proteomics of Chinese Ministry of Health, Xiangya \\ Hospital, Central South University, 87 Xiangya Road, Changsha, Hunan \\ 410008 P. R. China; \\ ${ }^{2}$ Hunan Engineering Laboratory for Structural Biology and Drug Design, \\ Xiangya Hospital, Central South University, 87 Xiangya Road, Changsha, \\ Hunan 410008 P. R. China; \\ ${ }^{3}$ State Local Joint Engineering Laboratory for Anticancer Drugs, Xiangya \\ Hospital, Central South University, 87 Xiangya Road, Changsha, Hunan \\ 410008 P. R. China; \\ ${ }^{4}$ The State Key Laboratory of Medical Genetics, Central South University, 88 \\ Xiangya Road, Changsha, Hunan 410008 P. R. China.
}

*Correspondence: Xianquan Zhan, Key Laboratory of Cancer Proteomics of Chinese Ministry of Health, Xiangya Hospital, Central South University, 87 Xiangya Road, Changsha, Hunan 410008 P.R. China. Tel: +86-731-48327905; Fax: +86-731-48327905; E-mail: yjzhan2011@gmail.com.

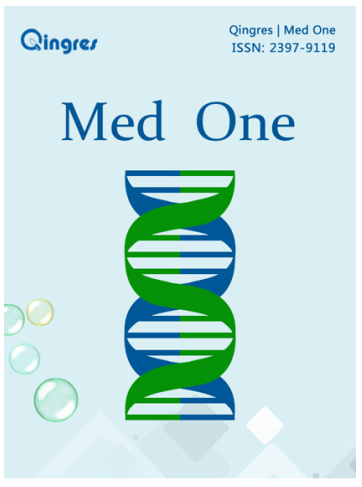

http://mo.qingres.com

\section{GOPEN ACCESS}

DOI: $10.20900 / \mathrm{mo} .20170027$

Received: October 19, 2017

Accepted: November 20, 2017

Published: November 29, 2017

Copyright: $\odot 2017$ Cain et al. This is an open access article distributed under the terms of the Creative Commons Attribution License,which permits unrestricted use, distribution, and reproduction in any medium, provided the original author and source are credited.

\begin{abstract}
The endogenous low-abundance tyrosine nitration in a proteome has sensitive biological effect and is a stable biomarker of oxidative/ nitrosative stress or injuries, which is closely associated with a wide spectrum of diseases. Some nitroproteomics approaches have been established to achieve the identity of nitoproteins and nitrotyrosine sites; however, high-throughput quantitative nitroproteomics is urgently needed to maximize the coverage of tyrosine nitration in a proteome. The hot research topics would be the competition of nitration and phosphorylation at the same tyrosine residue, and tyrosine nitration within important protein domains and motifs, with pathway network analysis, X-ray crystallography analysis, and fixed point mutation methods to reveal scientific merit of protein nitration in clarification of molecular mechanism of a disease and discovery of effective therapeutic targets. The tyrosine nitration pattern of biofluid might benefit the discovery of reliable biomarkers for accurately predictive, diagnosis, and prognosis assessment of a disease.
\end{abstract}

Keywords: Tyrosine nitration; Nitropeptide; Nitroprotein; Nitroproteome; Nitroproteomics; Nitropeptidomics; Structural nitroproteomics; Medical potential 


\section{NITROPROTEOME, NITROPROTEOMICS, AND ITS METHODOLOGICAL STATUS}

The nomenclature "nitroproteome" initially appeared in $2004^{[1]}$, which means all nitroproteins that are nitrotyrosine-containing proteins or nitrated proteins in a proteome. Nitroprotein is the addition of a nitro group $\left(-\mathrm{NO}_{2}\right)$ to the position 3 of the phenolic ring of tyrosine residue to form 3-nitrotyrosine residue in a protein. Nitroproteomics is the use of proteomics to study the nitroproteome, or the theory and methodology to study the nitroproteome ${ }^{[1,2]}$. Mass spectrometry (MS) is the key approach to identity of endogenous nitroprotein and nitrotyrosine sites for elucidation of biological functions of protein tyrosine nitration in a biological system; however, which is obviously challenged because of its various MS behaviors of the nitro group in a nitroprotein among different MS analyses and the extreme low-abundance ( 1 in 10 6 tyrosines) of endogenous nitrotyrosine residues in a proteome ${ }^{[3]}$. The various MS behaviors of nitroproteins require an optimal MS technical platform, and the low abundance of endogenous nitrotyrosine sites requires effectively preferential enrichment of nitroproteins or nitropeptides prior to MS analysis. Two-dimensional gel electrophoresis $(2 \mathrm{DE})^{[1,}$ ${ }^{4,5]}$ - or nitrotyrosine affinity column (NTAC) ${ }^{[2]}$ -based nitrotyrosine immunoaffinity approaches are effective in detection and enrichment of endogenous nitroproteins; however, low abundance of tryptic nitropeptides relative to nonnitrated tryptic peptides derived from a nitroprotein still limits the MS identification of a nitroprotein. Therefore, it is necessary to develop the preferential enrichment of tryptic nitropeptides prior to MS analysis; however, currently commercial anti-nitrotyrosine antibody at the level of nitropeptides is not easily available, most of the commercial anti-nitrotyrosine antibodies are at the level of nitroprotein. The instable MS behaviors of the nitro group $\left(-\mathrm{NO}_{2}\right)$ have driven some researchers to convert the nitro group $\left(-\mathrm{NO}_{2}\right)$ to the MS stable amino group $\left(-\mathrm{NH}_{2}\right)$ and derivation (such as biotin) of amino group for targeted enrichment of aminopeptides prior to MS analysis ${ }^{[6-8]}$; however, those methods generally worked well for in vitro nitrated proteins or nitrated proteome but not very good for identity of endogenous nitroproteins. Recently, super-high sensitivity $(\sim 1$ atmol) and high resolution mass spectrometer such as OrbiTrap Velos or Fusion worked well in identity of 2DE-detected and separated nitroproteins, but its throughput is limited by character of 2DE and relatively low amount of nitroproteins in a $2 \mathrm{DE}$ spot. We strongly believe that preferential enrichment of tryptic nitropeptides derived from a proteome coupled with a long time (such as 3-4 h) LC-ESI-
MS/MS on the super-high sensitivity and resolution mass spectrometer such as OrbiTrap Velos or Fusion plus label-free or stable isotope such as TMT or iTRAQ-labeling techniques ${ }^{[9,10]}$ will quantify and maximize the coverage of endogenous nitrotyrosine sites in a complex human proteome. A most newly nitropeptide-based enrichment in combination with label-free quantification significantly improved the identity of in vivo nitrotyrosine sites ${ }^{[11]}$. Currently, because most of commercial anti-nitrotyrosine antibodies are based on the level of nitroprotein, the availability of commercial anti-nitrotyrosine antibody at the level of nitropeptide is the key factor to achieve this goal. Therefore, the methodology of nitroproteomics needs to be improved significantly for its maximum application in the field of medicine.

\section{CHEMICAL AND PHYSICAL CHARACTERISTICS AND POTENTIAL BIOLOGICAL FUNCTIONS OF PROTEIN TYROSINE NITRATION}

Protein tyrosine nitration owns its specific characters. The addition of nitro group $\left(-\mathrm{NO}_{2}\right)$ to the phenolic ring of tyrosine residue in a protein results in the shift of the phenolic pKa value from 10 for tyrosine to the physiological $\mathrm{pH}$ range $\sim 7.1$ for nitrotyrosine. Thus, a nitrotyrosine residue is about $50 \%$ ionized to produce a negative charge at the physiological $\mathrm{pH}$ range. The nitro group is an electron-withdrawing group, which causes the decrease of the electrondensity of the phenolic ring of a tyrosine residue in a protein. Thus, if protein nitration occurs within the interacting region between an enzyme-substrate, receptor-ligand, antigen-antibody, or dimerization region, the decreased electron-density could diminish the interaction intensity (enzyme-substrate, receptor-ligand, antigen-antibody, or dimerization) to affect the functions of that protein ${ }^{[2]}$. Protein nitration also competes the same tyrosine residue site with phosphorylation within a tyrosine kinase phosphorylation motif ([R or K] - x2(3) - [D or E] - x3(2) - [Y]) to affect the signal transduction ${ }^{[12]}$. Moreover, the discovery of putative denitrase in a cell or tissue demonstrates that biological protein tyrosine nitration could be a specific, dynamic, and reversible process between nitration and denitration ${ }^{[13]}$. Therefore, protein tyrosine nitration in a biological system has extensively biological functions, which is not only a pathological consequence and a stable biomarker of oxidative/nitrative injuries, but also alters protein functions ${ }^{[14]}$ to involve multiple biological processes such as redox signaling and neurotransmission ${ }^{[15]}$, and associate multiple pathophysiological processes 
such as tumorigenesis ${ }^{[2,5]}$, inflammation-related diseases ${ }^{[16,17]}$, aging and aging-related diseases ${ }^{[18,19]}$, neurodegenerative disease ${ }^{[20]}$, cardiovascular disease ${ }^{[21,22]}$, kidney disease ${ }^{[23]}$, and diabetes ${ }^{[24]}$. It emphasizes the importance, scientific merit, and potential of identification and quantification of endogenous protein tyrosine nitration or nitroproteome in the field of medicine.

\section{ROS/RNS SYSTEM, GENERATION OF PROTEIN TYROSINE NITRATION, AND PATHOGENESIS OF A DISEASE}

Exploration of variations in nitroproteome provides numerous promising and potential in the field of medicine. Many reactive oxygen/nitrogen species (ROS, RNS) are generated in human tissues and cells in different pathophysiological conditions ${ }^{[15]}$, including superoxide, nitric oxide, nitrogen dioxide, peroxyl radical, hydroxyl radical, alkoyl radical, hydroperoxyl radical, hypochlorous acid, hydrogen peroxide, hypobromous acid, ozone, singlet oxygen, nitrosyl cation, nitrous acid, dinitrogen tetroxide, nitrosyl anion, dinitrogen trioxide, dinitrogen tetroxide, peroxynitrous acid, nitronium cation, alkyl peroxynitrites, and nitryl chloride. Those ROS and RNS mutually act in an ordered chemical reaction system ${ }^{[15]}$, and exit in the entire process of a disease from preclinical to clinical phases, and from occurrence, development, diagnosis, therapy to prognosis of a disease, which are all involved in oxidative/nitrosative stress, and damage to DNA, carbohydrates, lipids, and proteins. Among those ROS and RNS-involved chemical reactions, superoxide and nitric oxide react quickly to generate peroxynitrate that is an in vivo main nitrating reagent to induce the nitration of tyrosine residue in a protein ${ }^{[1,12]}$, which reaction can be inhibited by thiols (RSH) and elevated by $\mathrm{CO}_{2}$, other secondary nitrating reagents include nitrous acid ( $\mathrm{HONO}$ ), nitryl chloride $\left(\mathrm{NO}_{2} \mathrm{Cl}\right)$, and nitric acid $\left(\mathrm{HONO}_{2}\right)$. Tyrosine nitration in a protein is a chemically stable post-translational modification, a marker of oxidative/nitrosative stress or injuries. Therefore, the stable protein tyrosine nitration is a potential biomarker to detect onset, progression, and therapeutic efficacy. Moreover, protein tyrosine nitration alters protein functions and involves molecular mechanisms of a disease, clarification of protein targets of tyrosine nitration benefits insights into novel pathological mechanisms of a disease ${ }^{[25]}$. Furthermore, three-dimensional structural study of key nitroproteins and nitrotyrosine sites benefit the discovery of effective therapeutic targets.

\section{UNTAPPED POTENTIAL OF NITROTEOMICS IN MEDICINE}

Immunoaffinity analysis of protein tyrosine nitration only reveals the existence and semi-quantification of tyrosine nitration in a biological system ${ }^{[4,5]}$. Quantitative nitroproteomics can quantify the degree of protein tyrosine nitration and determine nitrotyrosine sites. The high sensitivity and resolution mass spectrometer, and development of antinitrotyrosine antibody at the level of nitropeptides will drive the development of quantitative nitroproteomics in the field of medicine. Tissue nitroproteomics has a potential in insight into novel pathological mechanisms, tyrosine nitration-involved molecular network variations, and discovery of effective therapeutic targets. Biofluid nitroproteomics has a potential in identity of protein tyrosine nitration profiles, molecular classification, tyrosine nitrationinvolved metabolomic network variations, and discovery of effective tyrosine nitration biomarkers for monitoring of onset, progression, and prognosis of a disease. Structural biology analysis of key nitroproteins has a potential in discovery of new therapeutic targets and development of new drugs.

Several evidences are taken here for potential of nitroproteomics in medicine. Tissue nitroproteomics of astrocytomas revealed 18 nitroproteins and 20 nitrotyrosine sites that associate multiple biological functions in astrocytomas ${ }^{[5]}$, and especially RNS inactivates wild-type p53 protein function through tyrosine nitration in human gliomas ${ }^{[26,27]}$. Moreover, morphology and functions of rat-glioma cell lines and mouse-neuroblastoma were induced to change with the amino acid analog 3-nitrotyrosine [28]; and detyrosination/retyrosination is involved in the migration capability of glioblastoma cells [29]. Tissue nitroproteomics of pituitary adenomas discovered 9 nitroproteins and 10 nitrotyrosine sites

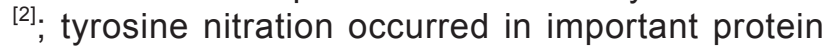
domains or motifs such as enzymatic activity region, dimerization region, transcriptional suppression domain, and tyrosine kinase phosphorylation motif; and protein nitration involves three important signaling pathway network systems including oxidative stress, cell-cycle dysregulation, and MAPKsignaling abnormality ${ }^{[30]}$. Biofluid nitroproteomics of chronic obstructive pulmonary disease (COPD) discovered 8 nitroproteins and 11 nitrotyrosine sites in bronchoalveolar lavage fluid (BALF) ${ }^{[12]}$, and protein nitration occurs within specific protein domain and motif and associates multiple 
functional metabolic systems such as mitochondrial dysfunction and energy metabolism, contractile protein function decrease, inflammatory immune changes, and hormone replacement therapy resistance. Nitroproteomics of aging at animal model revealed some multiple nitroproteins and nitrotyrosine sites and accumulation of protein nitration with aging ${ }^{[31]}$. Moreover, nitroproteomics discovered nitroproteins and nitrotyrosine sites in neurodegenerative diseases, cardiovascular diseases, and inflammation-related diseases ${ }^{[32]}$.

\section{CONCLUDING REMARKS}

The endogenous low-abundance tyrosine nitration in a proteome has sensitively biological effect and is a stable biomarker of oxidative/nitrosative stress or injuries, which associates a wide spectrum of diseases. Some nitroproteomics approaches have been established to achieve the identity of nitroproteins and nitrotyrosine sites; however, high-throughput quantitative nitroproteomics such as nitropeptide-based enrichment coupled with quantitative proteomics ${ }^{[11]}$ is urgently needed to maximize the coverage of tyrosine nitration in a proteome. For tissue nitroproteomics, it would be very interesting topic for competition of nitration and phosphorylation at the same tyrosine residue within tyrosine kinase phosphorylation motif, and tyrosine nitration within important protein domains such as enzymatic activity region, dimerization region, transcriptional suppression domain, and receptorligand interacting region. Pathway network analysis benefits the importance of nitroproteins in a biological system. Furthermore, structural biology such as X-ray crystallography analysis provides in-depth insight into influence of tyrosine nitration on structure and function of a protein to understand novel molecular mechanism and discover novel therapeutic targets. Biofuid nitroproteomics and nitropeptomics benefit the discovery of reliable tyrosine nitration biomarkers for accurately predictive, diagnosis, and prognosis assessment of a disease.

\section{ACKNOWLEDGEMENTS}

This work was supported by the National Natural Science Foundation of China (Grant No. 81572278 and 81272798 to $X Z$ ), the grants from China "863" Plan Project (Grant No. 2014AA020610-1 to XZ), the Xiangya Hospital Funds for Talent Introduction (to $X Z$ ), and the Hunan Provincial Natural Science Foundation of China (Grant No. 14JJ7008 to XZ).

\section{AUTHOR CONTRIBUTION}

X.Z. conceived the concept, collected pertinent references, designed and wrote the manuscript. S. Q., and Y. H. participated in collection of references and partial experiments. All authors approved the final manuscript.

\section{REFERENCES}

1. Zhan X, Desiderio DM. The human pituitary nitroproteome: detection of nitrotyrosyl-proteins with two-dimensional Western blotting, and amino acid sequence determination with mass spectrometry. Biochem Biophys Res Commun. 2004; 325: 1180-1186.

2. Zhan X, Desiderio DM. Nitroproteins from a human pituitary adenoma tissue discovered with a nitrotyrosine affinity column and tandem mass spectrometry. Anal Biochem. 2006; 354: 279289.

3. Zhan X, Wang X, Desiderio DM. Mass spectrometry analysis of nitrotyrosine-containing proteins. Mass Spectrom Rev. 2015; 34: 423448.

4. Zhan X, Desiderio DM. Linear ion-trap mass spectrometric characterization of human pituitary nitrotyrosine-containing proteins. Int J Mass Spectrom. 2007; 259: 96-104.

5. Peng F, Li J, Guo T, Yang H, Li M, Sang S, Li X, Desiderio DM, Zhan $X$. Nitroproteins in human astrocytomas discovered by gel electrophoresis and tandem mass spectrometry. J Am Soc Mass Spectrom. 2015; 26: 2062-2076.

6. Abello N, Barroso B, Kerstjens HAM, Postma DS, Bischoff R. Chemical labeling and enrichment of nitrotyrosine-containing peptides. Talanta. 2010; 80: 1503-1512.

7. Zhang Q, Qian WJ, Knyushko TV, Clauss TR, Purvine SO, Moore RJ, Sacksteder CA, Chin $\mathrm{MH}$, Smith DJ, Camp DG II, Bigelow DJ, Smith RD. A method for selective enrichment and analysis of nitrotyrosine-containing peptides in complex proteome samples. J Proteome Res. 2007; 6: 2257-2268.

8. Dremina ES, Li X, Galeva NA, Sharov VS, Stobaugh JF, Schoneich C. A methodology for simultaneous fluorogenic derivatizaiton and boronate affinity enrichment of 3-nirotyrosine containing peptides. Anal Biochem. 2011; 418: 184-196.

9. Chiappetta G, Corbo C, Palmese A, Galli F, 
Piroddi M, Marino G, Amoresano A. Quantitative identification of protein nitration sites. Proteomics. 2009; 9: 1524-1537.

10. Robinson RA, Evans AR. Enhanced sample multiplexing for nitrotyrosine-modified proteins using combined precursor isotopic labeling and isobaric tagging. Anal Chem. 2012; 84: 46774686.

11. Zhao $Y$, Zhang $Y$, Sun $H$, Maroto $R$, Brasier AR. Selective affinity enrichment of nitrotyrosinecontaining peptides for quantitative analysis in complex samples. J Proteome Res. 2017; 16: 2983-2992.

12. Zhan X, Desiderio DM. Nitroproteins identified in human ex-smoker bronchoalveolar lavage fluid. Aging Dis. 2011; 2: 100-115.

13. Deeb RS, Nuriel T, Cheung C, Summers B, Lamon BD, Gross SS, Hajjar DP. Characterization of a cellular denitrase activity that reverses nitration of cyclooxygenase. Am J Physiol Heart Circ Physiol. 2013; 305: H687-H698.

14. Ischiropoulos $\mathrm{H}$. Protein tyrosine nitration--an update. Arch Biochem Biophys. 2009; 484: 117121.

15. Dalle-Donne I, Scaloni A, Giustarini D, Cavarra E, Tell G, Lungarella G, Colombo R, Rossi R, Milzani A. Proteins as biomarkers of oxidative/ nitrosative stress in diseases: The contribution of redox proteomics. Mass Spectrom Rev. 2005; 24: 55-99.

16. Ghosh S, Janocha AJ, Aronica MA, Swaidani S, Comhair SAA, Xu W, Zheng L, Kaveti S, Kinter M, Hazen SL, Erzurum SC. Nitrotyrosine proteome survey in asthma identifies oxidative mechanism of catalase inactivation. J Immunol. 2006; 176: 5587-5597.

17. Parastatidis I, Thomson L, Burke A, Chernysh I, Nagaswami C, Visser J, Stamer S, Liebler DC, Koliakos G, Heijnen HF, Fitzgerald GA, Weisel JW, Ischiropoulos H. Fibrinogen beta-chain tyrosine nitration is a prothrombotic risk factor. $\mathrm{J}$ Biol Chem. 2008; 283: 33846-33853.

18. Kanski J, Schoneich C. Protein nitration in biological aging: Proteomic and tandem mass spectrometric characterization of nitrated sites. Methods Enzymol. 2005; 396:160-171.

19. Kanski J, Hong SJ, Schoneich C. Proteomic analysis of protein nitration in aging skeletal muscle and identification of nitrotyrosinecontaining sequences in vivo by nanoelectrospray ionization tandem mass spectrometry. J Biol Chem. 2005; 280: 24261-
24266

20. Danielson SR, Held JM, Schilling B, Oo M, GibsonBW, Andersen JK. Preferentially increased nitration of alpha-synuclein at tyrosine-39 in a cellular oxidative model of Parkinson's disease. Anal Chem. 2009; 81: 7823-7828.

21. Tao RR, Huang JY, Shao XJ, Ye WF, Tian Y, Liao MH, Fukunaga K, Lou YJ, Han F, Lu YM. Ischemic injury promotes Keap1 nitration and disturbance of antioxidative responses in endothelial cells: A potential vasoprotective effect of melatonin. J Pineal Res. 2013; 54: 271281.

22. Thomson L, Tenopoulou M, Lightfoot R, Tsika E, Parastatidis I, Martinez M, Greco TM, Doulias PT, Wu Y, Tang WH, Hazen SL, Ischiropoulos H. Immunoglobulins against tyrosine-nitrated epitopes in coronary artery disease. Circulation. 2012; 126: 2392-2401.

23. Piroddi M, Palmese A, Pilolli F, Amoresano A, Pucci P, Ronco C, Galli F. Plasma nitroproteome of kidney disease patients. Amino Acids. 2011; 40: 653-667.

24. Safinowski $M$, Wilhelm B, Reimer $T$, Weise A, Thome' N, Ha"nel H, Forst T, Pfu"tzner A. Determination of nitrotyrosine concentrations in plasma samples of diabetes mellitus patients by four different immunoassays leads to contradictive results and disqualifies the majority of the tests. Clin Chem Lab Med. 2009; 47: 483488.

25. DiDonato JA, Aulak K, Huang Y, Wagner M, Gerstenecker G, Topbas C, Gogonea V, DiDonato AJ, Tang WH, Mehl RA, Fox PL, Plow EF, Smith JD, Fisher EA, Hazen SL. Site-specific nitration of apolipoprotein A-I at tyrosine 166 is both abundant within human atherosclerotic plaque and dysfunctional. J Biol Chem. 2014; 289: 10276-10292.

26. Cobbs CS, Whisenhunt TR, Wesemann DR, Harkins LE, VanMeir EG, Samanta M. Inactivation of wild-type p53 protein function by reactive oxygen and nitrogen species in malignant glioma cells. Cancer Res. 2003; 63: 8670-8673.

27. Cobbs CS, Samanta M, Harkins LE, Gillespie GY, Merrick BA. MacMillan-Crow LA. Evidence for peroxynitrite-mediated modifications to p53 in human gliomas: possible functional consequences. Arch Biochem Biophys. 2001; 394: 167-172.

28. Zedda M, Lepore G, Gadau S, Manca P, Farina V. Morphological and functional 
changes induced by the amino acid analogue 3-nitrotyrosine inmouse neuroblastoma and rat glioma cell lines. Neurosci Lett. 2004; 363: 190193.

29. Rovini A, Gauthier G, Berges R, Kruczynski A, Braguer D, Honore S. Anti-migratory effect of vinflunine in endothelial and glioblastoma cells is associated with changes in EB1 C-terminal detyrosinated/tryrosinated status. PLoS One. 2013: 8: e65694.

30. Zhan X, Desiderio DM. Signaling pathway networks mined from human pituitary adenoma proteomics data. BMC Med Genomics. 2010; 3:
13.

31. Sharov VS, Galeva NA, Kanski J, Williams TD, Schoneich C. Ageassociated tyrosine nitration of rat skeletal muscle glycogen phosphorylase B: Characterization by HPLC-nanoelectrospraytandem mass spectrometry. Exp Gerontol. 2006; 41: 407-416.

32. Sacksteder CA, Qian WJ, Knyushko TV, Wang HW, Chin MH, Lacan G, Melega WP, Camp DG II, Smith RD, Smith DJ, Squier TC, Bigelow DJ. Endogenously nitrated proteins in mouse brain: Links to neurodegenerative disease. Biochemistry. 2006; 45: 8009-8022. 